\title{
A Concise and Practical Framework for the Development and Usability Evaluation of Patient Information Websites
}

\author{
L.W. Peute ${ }^{1,2,} ;$;.L. Knijnenburg ${ }^{1,2,3,}{ }^{*} ;$ L.C. Kremer ${ }^{3}$; M.W.M. Jaspers ${ }^{1,2}$ \\ ${ }^{1}$ Center for Human Factors Engineering of Health Information Technology (HIT-Lab), Academic Medical Center, University of Am- \\ sterdam, The Netherlands; \\ 2Dept. of Medical Informatics, Academic Medical Center, Amsterdam, the Netherlands; \\ ${ }^{3}$ Dept. of Pediatric Oncology, Emma's Children Hospital/Academic Medical Center, Amsterdam, The Netherlands; \\ *These authors contributed equally to the paper
}

\section{Keywords}

Patient education, childhood cancer, survivorship, website, human factors

\section{Summary}

Background: The Website Developmental Model for the Healthcare Consumer (WDMHC) is an extensive and successfully evaluated framework that incorporates user-centered design principles. However, due to its extensiveness its application is limited. In the current study we apply a subset of the WDMHC framework in a case study concerning the development and evaluation of a website aimed at childhood cancer survivors (CCS).

Objective: To assess whether the implementation of a limited subset of the WDMHC-framework is sufficient to deliver a high-quality website with few usability problems, aimed at a specific patient population.

Methods: The website was developed using a six-step approach divided into three phases derived from the WDMHC: 1) information needs analysis, mock-up creation and focus group discussion; 2) website prototype development; and 3) heuristic evaluation (HE) and think aloud analysis (TA). The HE was performed by three double experts (knowledgeable both in usability engineering and childhood cancer survivorship), who assessed the site using the Nielsen heuristics. Eight end-users were invited to complete three scenarios covering all functionality of the website by TA.

Results: The HE and TA were performed concurrently on the website prototype. The HE resulted in 29 unique usability issues; the end-users performing the TA encountered eleven unique problems. Four issues specifically revealed by HE concerned cosmetic design flaws, whereas two problems revealed by TA were related to website content.

Conclusion: Based on the subset of the WDMHC framework we were able to deliver a website that closely matched the expectancy of the end-users and resulted in relatively few usability problems during end-user testing. With the successful application of this subset of the WDMHC, we provide developers with a clear and easily applicable framework for the development of healthcare websites with high usability aimed at specific medical populations.

\section{Correspondence to:}

Linda W. Peute, PhD

Dept. of Medical Informatics, room J1B-115.1

Academic Medical Center Amsterdam

Meibergdreef 9

1105 AZ Amsterdam

The Netherlands

Telephone: +31 (0) 205665595

Fax:+31 (0) 206919840

Email: I.w.peute@amc.uva.nl
Appl Clin Inform 2015; 6: 383-399

http://dx.doi.org/10.4338/ACl-2014-11-RA-0109

received: November 25, 2014

accepted: April 9, 2015

published: June, 12, 2015

Citation: Peute LW; Knijnenburg SL; Kremer LC; Jaspers MWM. A concise and practical framework for the development and usability evaluation of patient information websites. Appl Clin Inf 2015; 6: 383-399 http://dx.doi.org/10.4338/ACl-11-RA-0109 


\section{Introduction}

In the Netherlands, almost 40 per 100,000 children and adolescents develop cancer each year[1]. Great improvements in treatment for malignant disease in childhood have led to a major increase in survival rates, up to $85 \%$ [1]. With the rise in survival, a new and quickly growing population of long term survivors of childhood cancer emerged. In a recent study, Geenen et al. found that $75 \%$ of all survivors suffer from at least one adverse event at a median follow-up of seventeen years, emphasizing the need for adequate life-long follow-up care [2]. The DCOG (Dutch Childhood Oncology Group) LATER (Long term effects after childhood cancer) project aims to follow-up all Dutch 5 -year survivors and screen them based on evidence-based guidelines to improve quality of care and to conduct clinical research [3-5]. Previous research showed that survivors of childhood malignancies are not well informed about their past disease and the potential late effects [6-8]. Due to the long intervals between and the limited time during follow-up visits, childhood cancer survivors may have a need for a more continuous source providing this information. As for instance Lewis showed, well informed patients tend to be more compliant to screening and therapy, facilitating earlier diagnosis and treatment of late toxicities of treatment[9]. Patient information websites allow patients to educate themselves using web-based, personalized information at the time and place of their preference $[10,11]$.

In 2007, Johnson and Turley presented the Website Developmental Model for the Healthcare Consumer (WDMHC), a framework for the user-centered, iterative design and development of healthcare websites [12]. This framework incorporates well-documented user-centered design principles aimed at assisting the development of websites for healthcare consumers in the broadest sense. Although the framework was successfully applied in practice during the redesign of a consumer health information website, it is too extensive for projects with a limited scope and with limited resources [13]. Specifically, for the current study we had a well-defined end-user population with a specific medical background and only limited resources available for website development and evaluation. We hypothesized that the deployment of a limited subset of the WDMHC principles would be sufficient for delivering a patient information website aimed at a small and well-defined population that meets the end-users' requirements and expectations by providing high-quality and trustable content and does so with a sufficient usability. To elucidate that not all elements of the WDMHC are relevant in each setting we, for example, mention the keystroke level model [14]. This usability method is applied in the WDMHC but focuses on efficiency of a given system, which was not relevant for this project due to its limited scope.

In most studies reporting on website development, different usability testing methods are employed in different phases of the software development process [15-18]. Often, usability inspection methods, like the heuristic evaluation, are used early in the development process, where system mock-ups and system prototypes are evaluated by usability experts, whereas end-user testing methods like the think aloud method are more often used later in the system's development process [15, 17]. A literature review by Jaspers showed that the think aloud method gains the best insights in the cognitive processes of end users, but at a high cost [19]. On the other hand the heuristic evaluation can also give good results at a much lower cost. However, it is known that the heuristic evaluation can find a broad range of cosmetic and minor problems which may disguise more severe problems [19].

In the present study we aimed to test the hypothesis that implementation of a subset of the WDHMC principles is sufficient for the development and evaluation of a patient information website aimed at a specific medical patient population, in our case long term childhood cancer survivors. Additionally we aimed to compare the surplus value of two widespread usability evaluation methods, the heuristic evaluation and the think aloud method, in the context of the deployed usercentered development approach. 


\section{Methods}

The original WDMHC framework consists of more than 15 steps conducted in four phases:

1. user-, task- and environmental analysis;

2. functional- and representational analysis and their relation to visual and content representation criteria; comparative analysis to similar websites;

3. cognitive walkthrough, keystroke level model, heuristic evaluation and incorporation of metrics and guidelines and

4. content-based testing, expert-based testing and user-based testing.

The multifaceted approach we undertook for the development of our website consisted of six steps in 3 phases:

1. information needs analysis, mock-up creation and focus group;

2. website prototype development;

3. heuristic evaluation and think aloud analysis.

The whole process is outlined in $>$ Figure 1 . The following sections will shortly describe the methods undertaken for each step.

\subsection{Information needs analysis}

Understanding the end-users' information needs as well as the required functionalities are prerequisites for delivering a website that end-users intend to visit. Based on a qualitative literature study investigating the attitudes towards information supply and expectations of follow-up of cancer survivors and their parents a structured questionnaire comprising 24 questions was developed to elucidate website requirements $[1,6-8,15]$. The questionnaire was sent out to 160 survivors of childhood cancer or their parents. We asked our respondents to score a 5-point Likert-scale on 22 items involving different kinds of (health) information and functionalities which might be of interest for survivors of childhood cancer or their relatives. The information needs analysis resulted in a prioritized list of information requirements for the website.

\subsection{Mock-up, focus group and prototype development}

The visual representation or design of the website and its content should be optimized to allow for an optimal match between functionality and structure on the one hand and the goals of its end-users on the other hand. Based on the prioritized list of information needs, a simple mock-up website was created depicting its main functionality, content and navigational structures. Subsequently, we organized a stakeholder focus group with all stakeholders in the development process. The aims of this focus group were to assess whether the prioritized requirements list gathered from the survivors' survey corresponded with end-users' expectations and to collect opinions on the mock-up website from different stakeholder perspectives. To allow for a friendly and open discussion environment, we decided to limit the amount of participants. We invited two childhood cancer survivors and two parents of survivors, who previously had responded to the questionnaire and were willing to participate to the development of the website. We also invited a pediatrician, a pediatric oncologist and two human factors engineering and usability experts. The childhood cancer survivors and the two parents were all knowledgeable in using the internet and in searching for health information online. By combining different viewpoints in a focus group the various information needs could be combined with clinical expertise and possibilities in design and opinions could be openly discussed. A trained focus group facilitator chaired the session using a structured agenda in combination with a brainstorm approach. This supported that all participants were free to discuss their opinions and make suggestions to our initial mock-up. Minutes of the focus group in combination with the initial information needs assessment were used as input for the development of a working prototype of the website. The development of the prototype was outsourced to an external web design company, who incorporated established website usability guidelines during the development process [20]. 


\subsection{Usability evaluation}

To evaluate the prototype website on its usability we aimed to compare two well-known methods from the field of usability engineering: the heuristic evaluation and the think aloud analysis [19, 21]. Although both methods are usually deployed in different stages of the software development life cycle, we were interested in the (additional) value in terms of differences in output of both methods from the viewpoint of the complete user-centered development approach.

\subsubsection{Heuristic evaluation}

In a heuristic evaluation (HE), usability evaluators inspect a system according to a predefined set of rules of thumb: heuristics. The most widespread set of heuristics was developed in the early nineties by Nielsen and Molich and consists of ten heuristics [22]. Each evaluator first assesses the system under investigation in a global way, to get an idea of structure and navigation of the system and then makes a second iteration to assess user interface elements in detail. All possible usability issues are written down and the severity of each issue is rated on scale from 0 (cosmetic) to 4 (catastrophic) [23]. For our heuristic evaluation three evaluators independently inspected the prototype website according to Nielsen's heuristics. All three were trained in usability evaluation and usability research and had domain expertise in the field of childhood cancer survivorship care.

\subsubsection{Think aloud method}

The think aloud method (TA) is a verbal report method that stems from the field of cognitive psychology. During a think aloud session, participants interact with a system according to predefined protocols/task scenarios while they verbalize their thoughts aloud. These verbalizations get recorded and in combination with the screen recordings of the users' website navigation patterns and their task performances, a deep insight can be gained into the system's usability and the related usability problems.

For this study we created four scenarios that covered all the functionality the website offered: using the late effects search structure, finding information about diagnoses and anti-cancer therapy, looking up outpatient clinic information, etcetera (see Appendix 1) ((Author: please check - no appendix provided)). We selected a representative sample of eight potential end-users, as this number would be sufficient to reveal over $90 \%$ of real usability problems, as empirically shown by Nielsen [24]. We visited the participants in their home situation as this was the intended environment where the website would be used. We used a mobile 'usability laboratory' consisting of a laptop with Morae $^{\mathrm{mit}}$ software (TechSmith Corp., Okemos, MI, USA) to capture the screen, mouse gestures and mouse clicks through screen recording and the participant's face and voice through an integrated webcam. After all task scenarios were completed, users were automatically presented a 10-item System Usability Scale questionnaire to get a quick insight in the user's perception of the prototype website usability [25].

All recorded data were analyzed with the Morae ${ }^{\mathrm{Tm}}$ software. Firstly, all occurrences of usability problems were marked by reviewing the recordings. From the list of all occurrences a coding scheme was developed bottom-up by one author by grouping all the unique usability problem types into categories. A second evaluator (SK) individually reviewed all recordings, marked all usability problem occurrences and used the coding scheme to categorize them. Results of both reviewers were compared and discrepancies were resolved by discussion.

\subsubsection{Assessment of the surplus value of both usability evaluation methods}

From the literature it is clear that the HE and the TA both have their proper uses in the software developmental lifecycle $[16,26-31]$.However, the costs associated with the TA are much higher than those of the HE. We aimed to compare the surplus value of each method in the perspective of our multi-faceted and user-centered approach. To assess possible differences in the detected problems by both methods, we qualitatively mapped the problems found with both methods on basis of the raw usability problem descriptions to each other. 


\section{Results}

\subsection{Information needs assessment}

One-hundred forty-five survivors or parents of survivors returned the questionnaire on information requirements $(90.6 \%)$. Of these 145 only 15 respondents $(10.3 \%)$ used the internet to look for information about late effects of childhood cancer, and only four (27\%) of them managed to find the information they were looking for. In contrast, only $4 \%$ of all respondents stated they would not visit a late effects information website when available. Table 1 presents all survivors' information need items with a mean rating of 'important' or higher. The complete results of the questionnaire have been presented elsewhere [32]. Total performance time of the information needs analysis, including development, validation testing and results analysis was about four months.

\subsection{Mock-up, focus group and prototype development}

Based on the items concerning survivors' information needs that are listed in $>$ Table 1 , we envisioned a website structure divided in six sections: Home, News, LATER Information, Outpatient Clinics, Links and Contact. As the need for tailored information supply among survivors is high whilst their prior knowledge of disease, treatment and risks of late effects is low, we devised a search structure where survivors could search information in a linked network of diagnoses, their associated treatments and the potential late effects caused by these treatments. This search structure was envisioned through three columns (diagnosis, treatment, late effects) with clickable data labels, where the selection of an item in one of the three columns would automatically filter the related items in the other two columns. A mock-up showing the envisioned website structure and the search structure was subsequently developed.

During the focus group the results of the information needs assessment were discussed and the mock-up of the website was presented. The proposed division into six sections was used as an interview guideline and each section was discussed separately. The survivors' response on the mock-up was very positive, even though the design was still very basic. Input from the survivors was useful in prioritizing the requirements. There were three main comments regarding the mock up website: firstly, there was a need for additional information on diagnoses and treatments apart from information on late effects; secondly, functionality to seek contact with a health care provider was not necessary, as the goal of the website was to inform survivors, not to facilitate contact between survivors and physicians. Also, the proposed functionality of a discussion board was discarded as there was an existing and well-visited discussion board on the website of the Dutch Childhood Cancer Parent Organization (DCCPO). Survivors also expressed the opinion that discussion boards should be separated from websites visited by health care professionals, to keep a sense of privacy. The third comment was that the communication of all information should be in a conservative manner, to focus on reassurance instead of giving rise to anxiety.

Based on the original requirements and the feedback from the focus group, an external web design company developed the first working prototype of the website, incorporating the suggested search structure for finding targeted information on late effects. All content for the website was generated and peer-reviewed by members of the Information Service of the DCOG LATER project in cooperation with the Dutch Childhood Cancer Parent Organization (DCCPO). Screenshots of the prototype can be found in $>$ Figure 2 and $>$ Figure 3.

\subsection{Usability evaluation}

\subsubsection{Heuristic evaluation}

Three double experts (usability experts with domain knowledge on childhood cancer survivorship) listed a total of 40 occurrences of usability issues according to the 10 heuristics described by Nielsen [23]. After removing duplicates, 29 issues represented unique problem types (average pairwise interrater agreement was 33,3\%, which depicts the average agreements of all possible pairs among evaluators). The usability problems with a severity rating higher than 2 and those problems found by more than 1 evaluator are listed in $>$ Table 2 . The problems rated as most severe were the fact that 
hyperlinks to external websites were not depicted as such and that using the back-button while browsing the search structure for finding targeted information on late effects and its underlying information pages did not function correctly. These issues could severely hamper the end user's website interaction experience. Other usability issues were related to design consistency over different pages (different colors for hyperlinks on different pages, the search box was placed on different positions), deviations from standard web design guidelines (the website's logo should be clickable to return the homepage) and the website's content (the explanation of the search structure's mechanism was regarded as too complicated for the target audience).

\subsubsection{Think aloud method}

The think aloud population consisted of five survivors and three parents of childhood cancer survivors. The age of the participants of childhood cancer survivors ranged between 20 and 25 years and indicated time since initial cancer diagnosis was 16 years. Parents of childhood cancer survivors ranged between 50 and 55 yrs. All participants had broadband connections available at home and used the internet for at least two hours a week. Education attainments of the participants were on a (university of) professional education level. Testing sessions lasted for approximately 30 minutes per participant. Participants expressed little difficulty with thinking out loud, although some of the testers had to be reminded to keep talking on multiple occasions during the session. The participants were considered representative for the end-user population of the website; their characteristics were overall comparable to the population characteristics of the questionnaire results that was sent out to childhood cancer survivors and parents.

In total the eight testers encountered 67 usability issue occurrences which could be classified into 11 unique problems ( Table 3) and four categories. System response concerned usability problems related to how the prototype website responded to actions taken by the participants. Problems that arose during navigation through the website were categorized as navigational problems and the category 'representation of content' comprised all usability problems relating to participants not understanding the presentation of certain website content. The fourth category comprised all usability problems concerning 'mismatches between system and user's expectations'.

The majority of the issues were encountered in the late effects information search structure. The most frequently occurring problem, encountered 12 times by $6 / 8$ users, was that users clicked on the search structure's list entries, assuming that that would take them directly to information of interest, while clicking on these entries only updated the selection of relevant links displayed below the search structure itself (Z4). Another major problem was that the selected entries in the diagnosis/ treatment/late effects list boxes were not persistent when using the browser's back button: depending on the used internet browser the search structure would either forget the previous user selection (Z3) or, if it did show, the results of that selection were not updated correspondingly (Z5). Also, the search bar that was incorporated to search on the overall website did not behave as the test users expected from an online search engine. Legitimate search queries, for instance for 'leukemia', did not retrieve relevant information, as the leukemia information on the site was actually a link to an external page on the site of the DCOG.

After the TA session all testers were asked to fill in the 10 question SUS questionnaire. An average SUS score of 79.7 (min: 47.5 max: 97.5) was the result, indicating subjective assessment of the prototype website's usability was high on average. The low SUS score (47.5) can be traced back to the specific session where treatment(s) and diagnosis information was not accessible since the DCOG site was offline during testing.

\subsubsection{Assessment of the surplus value of both usability evaluation methods}

- Table 4 lists a comparison of problems found in both the TA and the HE. All the major usability issues discovered in the heuristic evaluation were likewise revealed by the think aloud user test sessions and vice versa. The four additional issues revealed by heuristic evaluation concerned cosmetic design flaws, whereas the two additional problems revealed by think aloud were related to website content.

The time spent on both analyses differed a lot. The heuristic evaluation took each evaluator approximately one hour, after which it took another hour to aggregate the results, resulting in a total of four hours spent on the HE. The think aloud analysis cost around 30 minutes to perform, but took a 
lot more time to analyze: two evaluators both went through all the participant's audio-visual recordings to transcribe the usability problems the participants uncovered. This took at least another 30 minutes per participant per evaluator, even though we used a sophisticated software suite specialized at this kind of tasks. We estimate the total time spent on the think aloud analysis at least 30 hours (excluding travel time to/from the participants).

\section{Discussion}

In this study we successfully implemented a practical multi-faceted, user-centered and iterative development approach for the development of a patient information website aimed at childhood cancer survivors and their relatives. Due to the involvement of end-users from the start of the project on and continuing in every phase of the development, we were able to deliver a prototype website that closely matched the expectancy of the end-users and resulted in relatively few usability problems during end-user testing.

User-centered design is one of the critical factors for the success of a website development project. Te chance that the implemented solutions fulfill the needs of the end-users increases when end-users are involved throughout the development process. This will subsequently lead to user adoption and user goal realization [33]. The most comprehensive framework for website development that incorporates user-centered design is the Website Developmental Model for the Healthcare Consumer (WDMHC) [12]. This framework consists of more than fifteen methodological steps aimed to assist the development of websites for healthcare consumers in the broadest sense. Although these steps were shown to be successfully applicable in a case study on the redesign of consumer health information website [13], the model is too extensive for projects with a limited scope and with limited resources. By testing whether the implementation of the limited subset of the WDMHC resulted in a website with good usability, we provide developers with a small, clear and easily applicable framework for healthcare websites aimed at specific medical populations.

In the current study we showed that the deployment of a minimalist subset of the methods described in the WDMHC can also be sufficient to build a website revealing relatively few problems during end-user testing. For our subset of the WDMHC we decided a priori that we had to include at least one method for the requirements phase, the development phase and for the evaluation phase. We then selected those methods that we reckoned to give the highest additional value with the lowest associated costs. The only exception was the think aloud analysis, which is known to have high costs, as we wanted to include at least one end user evaluation method to test whether end-users could read, understand the website and would trust the website content. Of course the methods we used in our subset can be interchanged with similar methodologies. For example, Kinzie et al. earlier developed a website development framework that can be mapped to the WDMHC as well [33]. They also started with a needs assessment including interviews, surveys and focus groups, followed by solution identification and task analysis, and finally iterative cycles of website design (guided by website design guidelines), development, and evaluation using cognitive walkthroughs and think aloud end-user testing. We recommend that the choice of the methodologies used for the specific phases of the development process should be adapted to the characteristics and needs of an individual project.

Childhood cancer survivors are at risk for developing late adverse effects of their treatment [2]. However, they and their close relatives have little knowledge about these late effects, as well as about their initial diagnosis and the treatment they received $[8,34]$. These knowledge deficits may hamper survivors' abilities to engage in a healthy lifestyle, to participate in screening programs and to adequately be able to engage in self-management and self-care. Also, the uncertainty on what type of late effects is relevant for childhood cancer survivors might induce higher stress levels of parents and relatives. The results of the information needs assessment proved that survivors did indeed have unmet information needs regarding late effects of childhood cancer [32]. Respondents rated an extensive list of possible information items and website functionalities, resulting in a detailed prioritization of requirements for the website.

Focus groups, if used at all in the development process of health information websites, are often employed near the end of the process, after usability testing or during a redesign iteration $[16,35]$. 
We reckoned that a live meeting with all the stakeholders early in the development process would result in a more detailed specification of requirements, resulting in a closer match between website content, functionality and structure and end-users expectations and needs. The focus group proved worthwhile at this stage of the development: we gained additional insights regarding the requirements of the potential end-users. The participating survivors knew what information and functionality was already available online and which resources were still missing, enabling us to focus on the information and functionality with the highest priority in designing the website. Additionally, based upon the mockup, survivors were able to pinpoint possible (usability) problems with both the navigational structure of the site and search structure for late effects information before we even started building a prototype. The information gathered during these two initial phases was valuable for the development of the first version of the website.

Several studies have been performed comparing the performance of heuristic evaluation and think aloud analysis applied either concurrently or at different time points in the software development life [26-28]. In comparison to the think aloud analysis, heuristic evaluation is known to find a higher number of usability issues, with both low- and high severity, at much lower costs. Our results are in line with these common findings: the heuristic evaluation revealed many more, especially low-severity or cosmetic problems in comparison to the think aloud analysis at much lower cost. However, several studies state that end-user usability testing is imperative to uncover the remaining problems not found in heuristic evaluation [13, 16, 29-31]. This was not the case in our study. All but two issues encountered by end-users during testing were also covered by the heuristic evaluation. The two items solely found by participants of the TA were "Users think information about specific late effects is under general 'Information' header instead of under 'Late Effects' header" and "Use of unknown (medical) abbreviations". The domain knowledge and the involvement in the development process of the three double experts who performed the HE may explain that these two issues were overlooked in the heuristic evaluation. It should be noted that these two issues were the only ones found that related to readability, credibility, accuracy and understandability of the website's content. As they could be easily redesigned in the system they were classified as minor usability problems. However, for task performance they could be viewed upon as major issues negatively influencing the user experience. We think that the deployed methodology, in combination with the editing and peer-reviewing of the content by a team of medical professionals and members of the DCCPO, resulted in a website that end-user can read, understand and trust. Formal evaluation using validated measurements may be performed in future studies to confirm this.

The good results of the heuristic evaluation in comparison to the think aloud evaluation may have had several reasons. The user-centered approach, from the initiation of the project and onwards, may have led to a close match between the design and the end-users' strategies in approaching the website, resulting in less (severe) usability problems during testing. The inclusion of three evaluators knowledgeable both in usability evaluation studies and childhood cancer survivorship may also have contributed to the relatively better performance of the HE. Nielsen and Landauer found that, in a series of six heuristic evaluations of different user interfaces, the use of 5 evaluators resulted in a detection coverage of $75 \%$ of the usability problems [36]. Detection rates improve strongly though with the expertise of the evaluators: one skilled usability expert with additional medical knowledge regarding the application's content domain may account for up to $60 \%$ of all usability issues [36-38]. In situations that skilled usability evaluators are not familiar with the website's medical domain, a work-domain expert could assist the evaluator in tackling domain specific problems. These work domain experts in these so-called 'participatory heuristic evaluations' may help usability evaluators in considering how the system contributes in reaching certain goals in that particular area of skills [19].

A possible limitation of this study was the scope of the website under study. Use of the website was uncomplicated as the system mainly consisted of static information content with some dynamic behavior implemented through JavaScript. Of course appropriate usability testing is also essential for smaller websites, but future studies should investigate the reliability of our methodology when implemented for the development of more advanced healthcare websites. 


\section{Conclusion}

In conclusion, we implemented a practical, user-centered and iterative development methodology for the development of a patient information website for childhood cancer survivors. If time and resources are limited, heuristic evaluation with double experts may be sufficient to discover all usability problems on a patient information website. In our case all encountered usability problems have been translated into recommendations for redesign and were given as feedback to the website developers. The redesigned website was launched and in the final evaluation respondents were satisfied with its usability and contents [39]. As patient information websites should be designed to match end users' expectations, our approach can serve as a low-cost and practical framework for their development and evaluation. In the future, we aim to extend the current website to a patient portal where survivors can login to exchange medical record data with healthcare professionals and where they can receive truly tailored health information based on their electronic medical record.

\section{Clinical Relevant Statement}

This study is relevant for developers of e-health websites aimed at specific clinical populations by providing them a clear and easily applicable framework with specific focus on user centered design and usability.

\section{Human Subject Research Approval}

This study was exempted from human subject research approval. The authors declare that subject participation to this study was on a voluntary basis. Informed consent was obtained prior to participation.

\section{Conflict of interest statement}

The authors have declared no conflicts of interest.

\section{Acknowledgements}

We would like to thank all participants in this study for their support in the development and evaluation of the website. We would especially like to thank Jaldert R.J. van Beek for his involvement in this study; for his outstanding work and contributions to the analysis of the results and the performance of the focusgroup and evaluation study. 


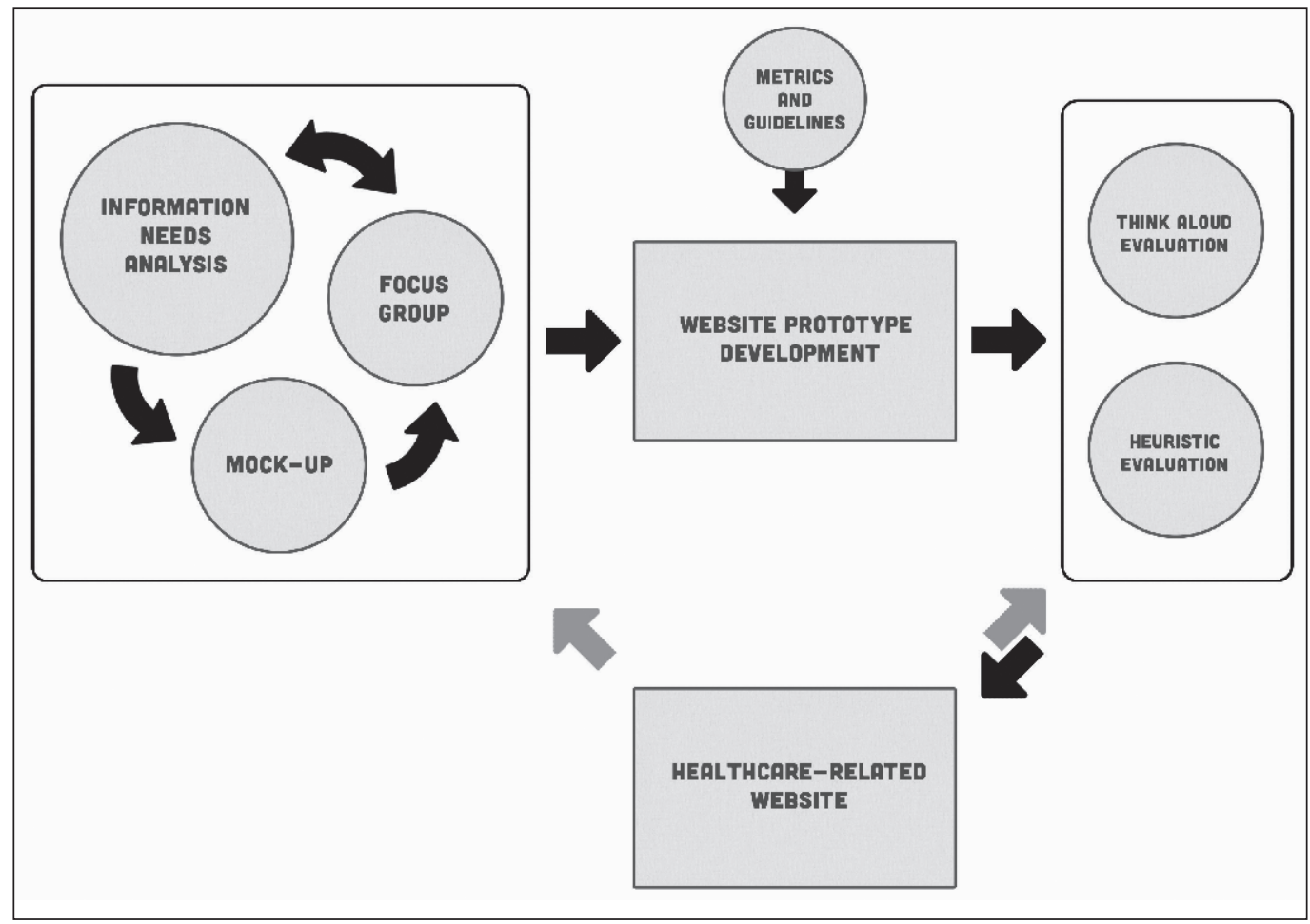

Fig. 1 Applied development process following a subset of the WDMHC-framework

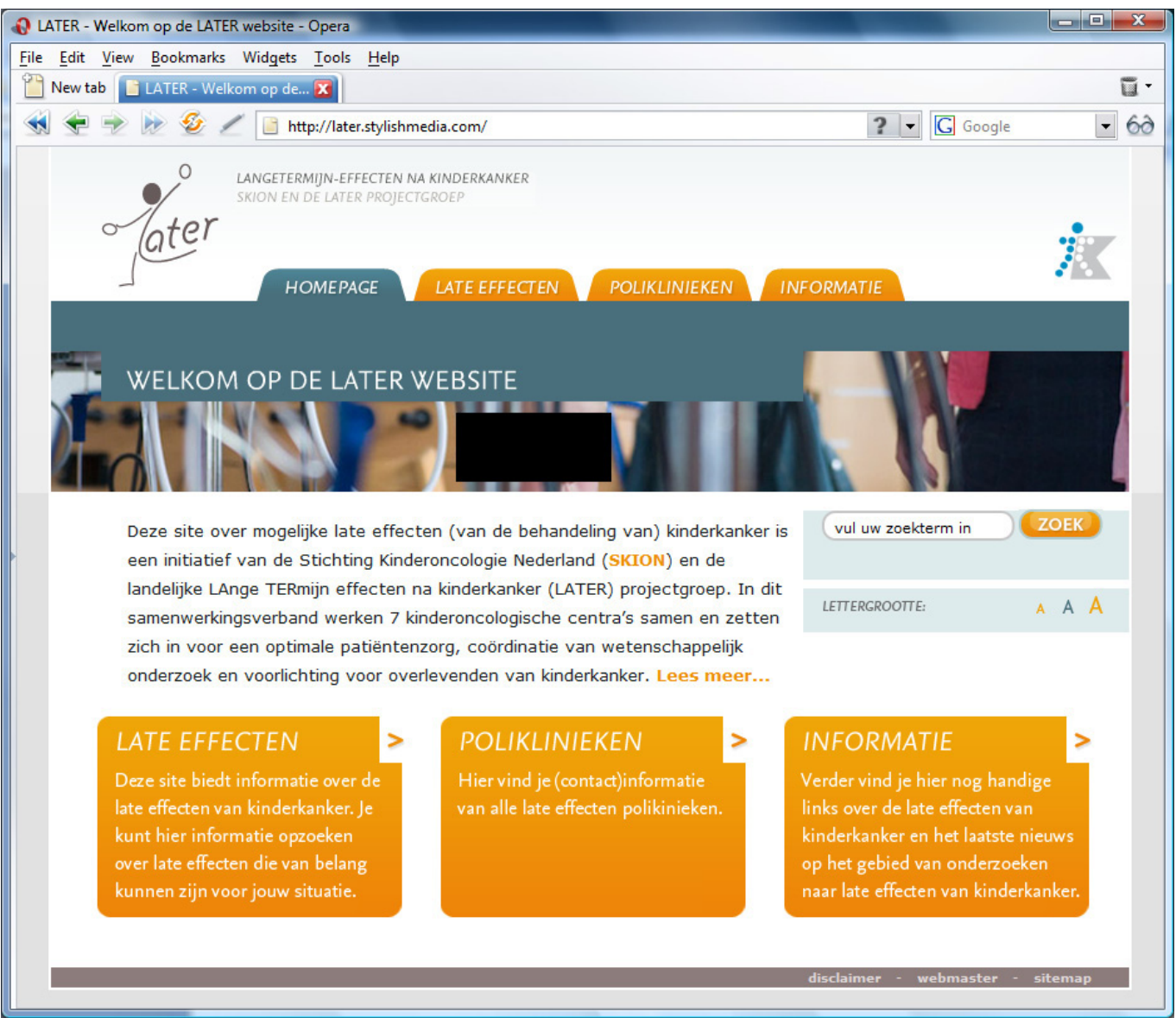

Fig. 2 Screenshot of the opening page of the prototype website for childhood cancer survivors 


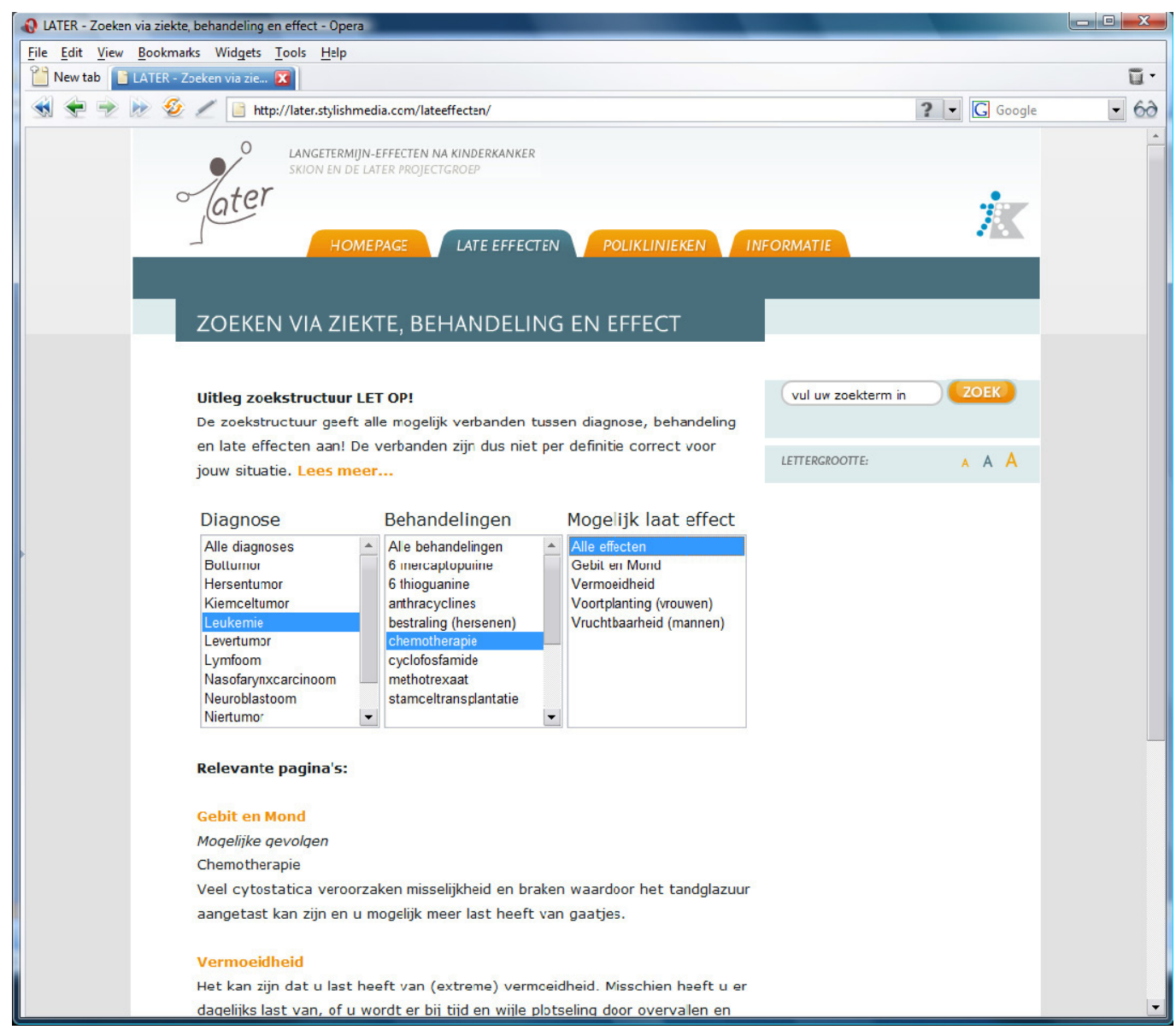

Fig. 3 Screenshot of the website search tool for childhood cancer effects and relevant information 
Table 1 Information- and functional requirements based on the information needs analysis

\begin{tabular}{|l|c|c|}
\hline Requirements for the website & Mean rating & SD \\
\hline Address of the specialized late effects outpatient clinic & 4.0 & 1.0 \\
\hline Phone number of the outpatient clinic & 4.2 & 0.9 \\
\hline Information about late effects tailored to your personal situation & 4.2 & 0.7 \\
\hline Information about all possible late effects & 4.1 & 0.8 \\
\hline Information about recognizing symptoms of possible late effects & 4.5 & 0.6 \\
\hline $\begin{array}{l}\text { Information on possible therapies for the late effects tailored to your specific } \\
\text { situation }\end{array}$ & 4.3 & 0.7 \\
\hline Information on possible therapies for all possible late effects & 4.1 & 0.8 \\
\hline Information about self-care to minimize the impact of possible late effect & 4.4 & 0.7 \\
\hline Up-to-date news about late effects of childhood cancer & 4.2 & 0.8 \\
\hline Information about the rights you have as a patient & 4.1 & 0.7 \\
\hline $\begin{array}{l}\text { Asking health-related/medical questions through email and receiving an answer } \\
\text { via email or telephone }\end{array}$ & 4.0 & 0.8 \\
\hline A search engine to search the site & & 4.0 \\
\hline
\end{tabular}

Rating were scored on a 5 point Likert scale (1: very unimportant to 5 : very important). Abbreviations: SD: standard deviation.

Table 2 Results of the heuristic evaluation

\begin{tabular}{|c|c|c|}
\hline Description of usability problem & $\begin{array}{l}\text { Mean severity } \\
\text { rating }\end{array}$ & $\begin{array}{l}\text { Evaluators } \\
\text { (found / total) }\end{array}$ \\
\hline External links are not clearly depicted as such & 3.5 & $2 / 3$ \\
\hline $\begin{array}{l}\text { Search structure 'back' doesn't function correctly; results and selec- } \\
\text { tions in tables change after 'back' }\end{array}$ & 3.5 & $2 / 3$ \\
\hline $\begin{array}{l}\text { Automatic change of results when using search structure is not visible } \\
\text { because the user needs to scroll down to see those changes }\end{array}$ & 3 & $1 / 3$ \\
\hline $\begin{array}{l}\text { Deeplink of diagnosis results on external site do not lead to relevant } \\
\text { information directly }\end{array}$ & 3 & $1 / 3$ \\
\hline Search bar only matches full strings & 2.5 & $2 / 3$ \\
\hline $\begin{array}{l}\text { 'all diagnosis/all...' selectable items in the search structure all seem } \\
\text { to be active and selected, but only 'all diagnosis' is really active and } \\
\text { selected. }\end{array}$ & 2 & $2 / 3$ \\
\hline No 'back' at search structure explanation & 2 & $2 / 3$ \\
\hline Colored blocks on homepage not clearly clickable & 2 & $1 / 3$ \\
\hline Inconsistent use of hyperlink colors & 2 & $1 / 3$ \\
\hline Inconsistent search box placement & 1.5 & $2 / 3$ \\
\hline Submenu is not clearly visible & 1.5 & $2 / 3$ \\
\hline $\begin{array}{l}2 \text { hyperlink lines in results of treatment, diagnosis which link to the } \\
\text { same site }\end{array}$ & 1 & $2 / 3$ \\
\hline Logo's on homepage not clickable & 1 & $2 / 3$ \\
\hline
\end{tabular}


Table 3 Results of the think aloud evaluation

\begin{tabular}{|c|c|c|c|c|c|}
\hline Division & $\begin{array}{l}\text { Coding } \\
\text { category }\end{array}$ & ID & Usability problem & $\begin{array}{l}\text { Total } \\
\text { occurrences }\end{array}$ & $\begin{array}{l}\text { Number of } \\
\text { testers } \\
\text { encountering } \\
\text { problem }\end{array}$ \\
\hline \multirow[t]{3}{*}{$\begin{array}{l}\text { Menu or } \\
\text { submenu }\end{array}$} & C & M1 & $\begin{array}{l}\text { Users think information about late effects } \\
\text { is found under 'information' }\end{array}$ & 5 & $5 / 8$ \\
\hline & C & M2 & $\begin{array}{l}\text { Outpatient clinic abbreviations are not } \\
\text { known to users }\end{array}$ & 2 & $2 / 8$ \\
\hline & $\mathrm{N}$ & M3 & Users cannot find/do not notice submenu & 4 & $4 / 8$ \\
\hline \multirow{7}{*}{$\begin{array}{l}\text { Search } \\
\text { structure }\end{array}$} & $\mathrm{N}$ & Z1 & User cannot return to previous page & 5 & $3 / 8$ \\
\hline & $\mathrm{N}$ & $\mathrm{Z2}$ & $\begin{array}{l}\text { User cannot proceed to full information } \\
\text { (read more) }\end{array}$ & 5 & $4 / 8$ \\
\hline & S & $\mathrm{Z3}$ & $\begin{array}{l}\text { Selection is gone after browser 'back', has } \\
\text { to be performed again }\end{array}$ & 10 & $6 / 8$ \\
\hline & $S$ & Z4 & User wants to display results by clicking & 12 & $6 / 8$ \\
\hline & $S$ & Z5 & $\begin{array}{l}\text { Users see a selection displayed, but this is } \\
\text { not actual active selection }\end{array}$ & 8 & $6 / 8$ \\
\hline & M & Z6 & $\begin{array}{l}\text { Users cannot distinguish which hyperlink } \\
\text { line leads to correct information }\end{array}$ & 3 & $3 / 8$ \\
\hline & M & $\mathrm{Z7}$ & $\begin{array}{l}\text { Users do not perceive links to external } \\
\text { websites as such }\end{array}$ & 4 & $4 / 8$ \\
\hline $\begin{array}{l}\text { Search } \\
\text { bar }\end{array}$ & $S$ & B1 & $\begin{array}{l}\text { Users do not get results with legitimate } \\
\text { search query }\end{array}$ & 9 & $7 / 8$ \\
\hline
\end{tabular}

Interrater agreement for categorization was $72 \%$, after which all discrepancies were resolved by discussion. Coding category abbreviations: C: representation of content; N: navigational options; S: system response; M: mismatch between system and user's expectations. 
Table 4 Comparison of the results of the think aloud analysis and the heuristic evaluation.

\begin{tabular}{|c|c|c|c|}
\hline $\begin{array}{l}\text { Think aloud usability problem } \\
\text { descriptions }\end{array}$ & $\mathbf{N}$ & $\begin{array}{l}\text { Associated findings of the heuristic } \\
\text { evaluation }\end{array}$ & $S$ \\
\hline $\begin{array}{l}\text { Users think information about late effects is } \\
\text { under general 'Information' header }\end{array}$ & 5 & & \\
\hline Use of unknown (medical) abbreviations & 2 & & \\
\hline Users cannot find/do not notice submenu & 4 & Submenu is not clearly visible & 1.5 \\
\hline User cannot return to previous page & 5 & No 'Back' at search structure explanation & 2 \\
\hline $\begin{array}{l}\text { User cannot proceed to full information (read } \\
\text { more link)User wants to display results by } \\
\text { clicking }\end{array}$ & 512 & $\begin{array}{l}\text { Automatic change of results not clear when } \\
\text { using search structure }\end{array}$ & 3 \\
\hline $\begin{array}{l}\text { Selection is gone after browser 'back', reselec- } \\
\text { tion needed }\end{array}$ & 10 & $\begin{array}{l}\text { Search structure 'Back' doesn't function cor- } \\
\text { rectly }\end{array}$ & 3.5 \\
\hline $\begin{array}{l}\text { Users see a selection displayed, which is not } \\
\text { the actual active selection }\end{array}$ & 8 & $\begin{array}{l}\text { 'all diagnosis/all...' selectable items in the } \\
\text { search structure seem to be all active, but only } \\
\text { 'all diagnosis' is really active and selected }\end{array}$ & 2 \\
\hline $\begin{array}{l}\text { Users cannot distinguish which hyperlink line } \\
\text { leads to correct information }\end{array}$ & 3 & 2 hyperlink lines linking to the same site & 1 \\
\hline $\begin{array}{l}\text { Users do not perceive external links as such } \\
\text { (and get lost) }\end{array}$ & 4 & $\begin{array}{l}\text { External links are not depicted as such } \\
\text { Deep link of diagnosis results on external site } \\
\text { do not lead to relevant information directly }\end{array}$ & $\begin{array}{r}3.5 \\
3\end{array}$ \\
\hline \multirow[t]{5}{*}{$\begin{array}{l}\text { Users do not get results with legitimate search } \\
\text { query }\end{array}$} & 9 & Search bar only matches full strings & 2.5 \\
\hline & & $\begin{array}{l}\text { Colored blocks on homepage not clearly click- } \\
\text { able }\end{array}$ & 2 \\
\hline & & Inconsistent use of hyperlink colors & 2 \\
\hline & & Inconsistent placement of search box & 1.5 \\
\hline & & Logo's on homepage not clickable & 1 \\
\hline
\end{tabular}

$\mathrm{N}$ : the amount of occurrences of the usability problem found by think aloud analysis. S: Severity score of the usability problem found by heuristic evaluation 


\section{References}

1. Heymans HS, Caron HN. Childhood cancers in the Netherlands (1989-1997). Ned Tijdschr Geneeskd 2001: 145: 1442-1444. PM:11503310

2. Geenen MM, Cardous-Ubbink MC, Kremer LC, van den Bos C, van der Pal HJ, Heinen RC, Jaspers MW, Koning CC, Oldenburger F, Langeveld NE, Hart AA, Bakker PJ, Caron HN, van Leeuwen FE. Medical assessment of adverse health outcomes in long-term survivors of childhood cancer. JAMA 2007: 297: 2705-2715. PM:17595271

3. Jaspers MW, Van den Bos C, Heinen RC, Bakker PJ, Geenen MM, Kremer LC, Van Leeuwen F, Caron HN. Development of a national protocol to screen Dutch cancer survivors on late cancer treatment effects. Int J Med Inform 2007: 76: 297-305. PM:16533618

4. Jaspers MW, Caron H, Behrendt H, van den Bos C, Bakker P, Van Leeuwen F. The development of a new information model for a pediatric cancer registry on late treatment sequelae in The Netherlands. Stud Health Technol Inform 2000: 77: 895-899. PM:11187683

5. Kremer LCM, Jaspers MWM, van Leeuwen FE, et al. Landelijke richtlijnen voor follow-up van overlevenden van kinderkanker. Tijdschrift voor Kindergeneeskunde 2006: 74: 214-218.

6. Byrne J, Lewis S, Halamek L, Connelly RR, Mulvihill JJ. Childhood cancer survivors' knowledge of their diagnosis and treatment. Ann Intern Med 1989: 110: 400-403. PM:2916808

7. Bashore L. Childhood and adolescent cancer survivors' knowledge of their disease and effects of treatment. J Pediatr Oncol Nurs 2004: 21: 98-102. PM:15125553

8. Kadan-Lottick NS, Robison LL, Gurney JG, Neglia JP, Yasui Y, Hayashi R, Hudson M, Greenberg M, Mertens AC. Childhood cancer survivors' knowledge about their past diagnosis and treatment: Childhood Cancer Survivor Study JAMA 2002: 287: 1832-1839. PM:11939869

9. Lewis D. Computer-based approaches to patient education: a review of the literature. J Am Med Inform Assoc 1999: 6: 272-282. PM:10428001

10. Tuil WS, ten Hoopen AJ, Braat DD, de Vries Robbé PF, Kremer JA. Patient-centred care: using online personal medical records in IVF practice. Hum Reprod 2006: 21: 2955-2959. PM:16982658

11. Grant RW, Wald JS, Poon EG, Schnipper JL, Gandhi TK, Volk LA, Middleton B. Design and implementation of a web-based patient portal linked to an ambulatory care electronic health record: patient gateway for diabetes collaborative care. Diabetes Technol Ther 2006: 8: 576-586. PM:17037972

12. Johnson CM, Turley JP. A new approach to building web-based interfaces for healthcare consumers. Elec J Health Inform 2007: 2: e2. http://www.ejhi.net

13. Taylor HA, Sullivan D, Mullen C, Johnson CM. Implementation of a user-centered framework in the development of a web-based health information database and call center. J Biomed Inform 2011: 44: 897-908. PM:21396486

14.Dix A, Finlay J, Abowd GD, Beale R. Cognitive models. In. Human-Computer Interaction. Harlow, United Kingdom: Pearson Education Limited; 2004. p 436-441. ISBN: 0130-461091.

15. Ruland CM, Jeneson A, Andersen T, Andersen R, Slaughter L, Bente-Schjødt-Osmo, Moore SM. Designing tailored Internet support to assist cancer patients in illness management. AMIA Annu Symp Proc 2007: 635-639. PM:18693913

16. Grama LM, Beckwith M, Bittinger W, Blais D, Lollar C, Middleswarth A, Noone M, Price D, Quint-Kasner S, Shields V, Wright LW. The role of user input in shaping online information from the National Cancer Institute. J Med Internet Res 2005: 7: e25. PM:15998616

17. Sox CM, Gribbons WM, Loring BA, Mandl KD, Batista R, Porter SC. Patient-centered design of an information management module for a personally controlled health record. J Med Internet Res 2010: 12: e36. PM:20805091

18. Kushniruk AW, Patel VL, Cimino JJ. Evaluation of Web-based patient information resources: application in the assessment of a patient clinical information system. Proc AMIA Symp 2000: 443-447. PM:11079922

19. Jaspers MW. A comparison of usability methods for testing interactive health technologies: Methodological aspects and empirical evidence. Int J Med Inform 2008. PM:19046928

20. Nielsen J. Designing Web Usability. Indianapolis: New Riders Publishing; 1999. ISBN: < [26] ISSN/ISBN>.

21. Joshi A, Arora M, Dai L, Price K, Vizer L, Sears A. Usability of a patient education and motivation tool using heuristic evaluation. J Med Internet Res 2009: 11: e47. PM:19897458

22. Nielsen J, Molich R. Heuristic evaluation of user interfaces. In. ACM INTERCHI'93 Conference on Human Factors in Computing Systems. New York: ACM Press; 1990. p 249-256.

23. Nielsen J. Heuristic Evaluation. In: John Wiley \& Sons, editor. Usability Inspection Methods. New York; 1994. p 25-62

24. Nielsen J. Estimating the Number of Subjects Needed for A Thinking Aloud Test. International Journal of Human-Computer Studies 1994: 41: 385-397. ISI:A1994PR10100006 
25. Brooke J. SUS: a „quick and dirty“ usability scale. In: Jordan P, Thomas B., Weerdmeester B., McClelland A., editors. Usability Evaluation in Industry. London: Taylor and Francis; 1996

26. Law ELC, Hvannberg ET. Complementarity and Convergence of Heuristic Evaluation and Usability Test: A Case Study of UNIVERSAL Brokerage Platform. NordiCHI 2002: 71-80.

27.Fu LM, Salvendy G, Turley L. Effectiveness of user testing and heuristic evaluation as a function of performance classification. Behaviour \& Information Technology 2002: 21: 137-143. ISI:000177523400005

28. Beuscart-Zephir MC, Leroy N, Alao O, Darmoni S. Usability assessment study of a web site displaying medical resources on line: the CISMeF. Stud Health Technol Inform 2002: 90: 133-137. PM:15460675

29. Ostergren MJ, Karras BT. ActiveOptions: leveraging existing knowledge and usability testing to develop a physical activity program website for older adults. AMIA Annu Symp Proc 2007: 578-582. PM:18693902

30.Nahm ES, Preece J, Resnick B, Mills ME. Usability of health Web sites for older adults: a preliminary study. Comput Inform Nurs 2004: 22: 326-334. PM:15602301

31.Lai TY. Iterative refinement of a tailored system for self-care management of depressive symptoms in people living with HIV/AIDS through heuristic evaluation and end user testing. Int J Med Inform 2007: 76 (Suppl. 2): S317-S324. PM:17616431

32. Knijnenburg SL, Kremer LC, Van den Bos C, Braam KI, Jaspers MW. Health information needs of childhood cancer survivors and their family. Pediatr Blood Cancer 2010: 54: 123-127. PM:19743299

33. Kinzie MB, Cohn WF, Julian MF, Knaus WA. A user-centered model for web site design: needs assessment, user interface design, and rapid prototyping. J Am Med Inform Assoc 2002: 9: 320-330. PM:12087113

34. Hess SL, Johannsdottir IM, Hamre H, Kiserud CE, Loge JH, Fosså SD. Adult survivors of childhood malignant lymphoma are not aware of their risk of late effects. Acta Oncol 2011: 50: 653-659. PM:21261507

35. Ossebaard HC, Seydel ER, van Gemert-Pijnen L. Online usability and patients with long-term conditions: A mixed-methods approach. Int J Med Inform 2012: 81: 374-387. PM:22261086

36. Nielsen J, Landauer TK. A mathematical model of the finding of usability problems. In. CHI '93. New York, NY, USA: ACM; 1993. p 206-213.

37.Nielsen J. Usability Evaluation and Inspection Methods. In: Ashlund S, Mullet K., Henderson A., et al., editors. Reading, MA: Addison-Wesley; 1993.

38. Lathan CE, Sebrechts MM, Newman DJ, Doarn CR. Heuristic evaluation of a web-based interface for internet telemedicine. Telemed J 1999: 5: 177-185. PM:10908430

39. Knijnenburg SL, Kremer LC, Versluys AB, Braam KI, Mud MS, van der Pal HJ, Caron HN, Jaspers MW.. Evaluation of a patient information website for childhood cancer survivors. Support Care Cancer 2012. PM:23007883 


\section{Appendix 1: Think aloud tasks}

Practice task:

Use your web browser to search the internet for information regarding late effects of childhood cancer.

\section{1)Information on late effects}

a)You are a (parent of a) survivor of childhood cancer who had leukemia and you want to search information regarding late effects that are relevant to your disease. Try to find that information on the website.

b) After you searched for the late effects information you would like to find some information on your initial diagnosis. Search for this information on the website.

c) Finally, you want to know some details about two therapies you received: a stem cell transplantation and chemotherapy. Try to find this piece of information too.

d)Please repeat step a to $\mathrm{c}$ but take your own situation as a starting point.

2)Outpatient clinics

Five years ago, your oncologist told you you were fully cured. Now you read somewhere about the existence of late effects outpatient clinics and you want to know more information: you wonder how the clinic works and who you need to contact for an appointment.

3)Information on the LATER project

From your attending doctor you hear about the DCOG LATER project. You would like to find out more information about this project. Search the LATER website for detailed information about the project.

\section{4)More information online}

By now you found a lot of information on late effects on the website already and it grabbed your attention. Now you wonder if there are other sources of information online. Search the website for additional sources of information. 